\title{
Understanding Selfhood to Elucidate the Phenomenology of Mindfulness
}

\author{
Joe Higgins $^{1}[$
}

Received: 17 December 2021 / Revised: 7 January 2022 / Accepted: 27 January 2022 /

Published online: 26 February 2022

(C) The Author(s) 2022

\begin{abstract}
The health benefits of practising mindfulness are well documented, yet the phenomenological mechanisms of such practice remain under-theorised from both ontogenetic and social perspectives. By leveraging an enactive perspective on selfhood, these lacunae can be addressed: firstly, it is argued that proper understanding of mindfulness - and the health benefits that mindfulness practices seek - relies on recognising the socio-embodied nature of the self; consequently, occasions in which the therapeutic need for mindfulness are most pressing will be shown to be inextricably tied to socio-embodied fluctuations across different stages of life. What emerges is a phenomenological understanding of mindfulness as allowing one to dwell in the sensuous density of the present and, through this, remain connected to the social world of open possibilities.
\end{abstract}

Keywords Selfhood $\cdot$ Mindfulness $\cdot$ Phenomenology $\cdot$ Enactivism $\cdot$ Social ontology

\section{Introduction}

There is a wide and deep range of evidence for the general health benefits of practising mindfulness, encompassing coping with stress (Cahn and Polich, 2006), preventing depressive relapse (Godfrin and van Heeringen, 2010), relationship satisfaction (Wachs and Cordova, 2007), improved wellbeing (Carmody \& Baer, 2008), and enhanced immune system responsiveness (Grossman, Niemann, Schmidt, \& Walach, 2004). In spite of this, mindfulness remain under-theorised across academic disciplines and professional therapies: although detailed neuroscientific data (Brefczynski-Lewis et al., 2007; Ivanowski \& Malhi, 2007) and therapeutic case studies exist (Lomas et al., 2017), these studies fail to elucidate the holistic nature of mindfulness as affecting the whole person, rather than being merely neurologically or

Joe Higgins

bjoehiggins15@gmail.com

1 Northumbria University, Newcastle Upon-Tyne, UK 
discursively influential. Existing studies also generally fail to address the underlying foundations of mindfulness, focusing instead on its outcomes.

Philosophy is well poised to rectify these theoretical lacunae: since Socrates, philosophy has been concerned with 'the good life' and how it can be achieved - questions that, at heart, are concerned with the holistic wellness that mindfulness cultivates.

However, there is a fundamental problem with most philosophical approaches to wellness in that responses to the question of how to achieve wellness generally follow a set pattern: life aims at some ultimate goal (e.g. pleasure, utility, reason or morality) and all activities ultimately contribute to this goal. Such responses wrongly rely on an essentialist view of human life which asserts the existence of predetermined human nature, therein providing a model, in the form of essence or telos, to which existence must attempt to conform. The incorrect foundations of this approach filter through to all considerations of wellness, including health benefits that may be afforded through mindfulness. If one turns from this essentialist philosophy and towards phenomenology (and its modern counterpart: $4 E^{1}$ philosophy of mind), then we find that one's existence is not set by the model of predetermined nature; instead, each individual continually generates their own goals through interactions with others and the environment. What makes us well must therefore be tied to the temporal, physical and social conditions of different stages of life, and, crucially, proper elucidation of such conditions generates a robust model for theorisation of mindfulness.

To achieve such elucidation, this paper will take the following form. Firstly, I will argue for the phenomenologically inspired view that bodily processes and social processes are not taxonomically distinct concepts; instead, lived bodily processes are inevitably socially constituted and social processes are inevitably bodily constituted (Sect. 2). This view will develop through the lens of enactivism and will draw on robust evidence from neuroscientific research, leading to a reformulation of the concept selfhood. This is highly important in that it is rarely acknowledged that (i). there is an exhaustive permeation of one's embodied nature by social processes that one actively engenders through participation with others, and (ii). consideration of mindfulness - and the wellbeing that mindfulness practices seek - is contingent on proper understanding of the self. Accordingly, in Sect. 3, it will be demonstrated that impairments of wellbeing that often lead people to engage with mindfulness are inextricably tied to socio-embodied fluctuations across different stages of life: infancy, adolescence and old age will be investigated. In Sect. 4, a brief consideration of the phenomenology of depression will expound the manner in

\footnotetext{
1 '4E' philosophy refers to accounts of the mind as embodied, embedded, extended and enactive. It can be considered a modern counterpart to phenomenology in that $4 \mathrm{E}$ practitioners have drawn heavily on phenomenological concepts (e.g. Varela, Thompson \& Rosch (1991); Thompson (2007); Marratto (2012). Conversely, recent attempts have been made to inform phenomenological qualitative research through 4E approaches to mind (e.g. Stillwell and Harman (2021)). There is thus theoretical and practical affinity between phenomenology and $4 \mathrm{E}$ philosophy, encapsulated by the ongoing mutually illuminating dialogue between the two.
} 
which mindfulness allows one to dwell in the sensuous density of the present and, through this, remain connected to the social world of open possibilities.

The final hypothesis is, therefore, that practising mindfulness is a re-entering of one's socio-embodied self: grounding one's physical being as the origin and nexus of collectively mediated social meaning. In this way, one eludes rumination on potentially harmful, socially permeated thought cycles, whilst, simultaneously, indulging wellbeing-boosting awareness of one's sensory presence in the social world.

\section{Phenomenology, Enactivism and the Socio-Embodied Self}

A stalwart claim of phenomenology, perhaps reaching its clearest exposition in Sartrean existentialism, is the idea that selfhood is a phenomenon of continual formation and maintenance through dynamic interaction with the surrounding world. So, for instance, Husserl describes how consciousness (including selfhood), inheres in our direct experiential openness to the world and, as such, it is a property of categorical mind-world relationality, rather than a property of an independent Cartesian mind (Dreyfus \& Haugeland, 1978). Taking this further, Heidegger claims that each human being is not merely 'in' the world as per a spatial relationship, but dwells "in-the-world" in such a way that entities are meaningfully lived (through and with), rather than simply encountered $(1927 / 1962,54)$. In the sense of being inherently concerned with one's meaningful surroundings, Heidegger further explains that humans are "world-forming" (ibid., 1995, 177). Sartre then adopts this rationale to assert in the clearest terms that each human being, as "thrown into this world" $(1946 / 2007,5)$, becomes his own "project[...that] only attain[s] existence when he is what he purposes to be" (ibid., 3). In other words, it is by projecting oneself into, and engaging with, one's world that agents exist qua humans, and such projection and engagement are only initially possible in virtue of one's already meaningfully belonging to a world that can be brought to bear on present and future actions. Whilst there are nuanced differences between all of these claims, the ontological consensus is that the self is not a disembodied, isolated being who computationally represents a world through discrete propositions but, instead, is an environmentally embedded subject who enacts a meaningful world through purposively configured and historically sedimented expertise. Accordingly, from an epistemological perspective, selfhood need not arise with conscious relations to one's own cognitive representations; rather, it emerges primordially from an agent's meaningful prereflective relations with the surrounding world.

In modern philosophy, such phenomenological views have a kindred spirit in the '4E turn' within cognitive science, with the paradigm of enactivism perhaps providing closest theoretical affinity (Gallagher, 2018). For enactivism, an agent is always "bringing forth" a world by actively generating meaning through environmental interactions (Capra, 1996; Thompson, 2007; Varela et al., 1991). ${ }^{2}$ According to

\footnotetext{
2 There are various forms of enactivism (see Ward, Silverman and Villalobos (2017)). The variety considered in this paper is autopoietic enactivism.
} 
enactivists, there is continuity between life and mind, in that "cognition is grounded in the dynamics of biological life itself" (Ward et al., 2017, 370). Specifically, the contention is that any entity achieves autonomy by metabolising material resources from the surrounding environment in a manner that is unique to its own survival needs, thereby establishing a "functional identity" that is distinct from the outside world (Jonas, 1966/2001). Thus, there is a recursive process of emergence from the material environs on which an entity depends: sustenance from surroundings allow the manifestation of a systemic unity that continuously generates options for further environmental interactions (ibid.). The ongoing momentum of this recursive process of self-generation and self-identification means that the entity has an individual 'perspective' through which sustained environmental perturbations will be dealt with so as to uphold self-preservation (Di Paolo, 2005). It is this specific form of self-preservation - self-individuation - that amounts to autonomy, and it applies to all living entities, even those that are only passively subject to environmental perturbations. If an entity is able to actively modify its engagement so as to further preserve its self-individuation as a systemic unity - for example, by propelling itself in a certain direction - then it displays the adaptivity that is central to cognition, hence the aforementioned claim for continuity between life and mind (ibid.; Thompson, 2007).

As complex as the enactive paradigm can be, the central idea remains beautifully simple: living beings cognise through sensorimotor patterns of dynamics. This idea is a natural bedfellow for phenomenology, providing a biological basis for the phenomenological stance that humans are always meaningfully in-the-world (conversely, phenomenology can provide a philosophical basis for biological claims (Jonas, 1966/2001; Thompson, 2007)). Any entity that achieves adaptivity can be said to have a kind of 'minimal self' that is vitally embodied and embedded in its surrounding world.

In spite of the embodiment that is inherent to enactivism, the exact relationship between this embodiment and sociality remains a contentious issue (see Abramova and Slors (2019), Casper (2019), De Bruin and De Haan (2012)) and its resolution is a key facet of this paper's novel approach to selfhood. Drawing on the aforementioned contentiousness, the suggestion is that enactivists' consideration of our 'worldedness' needs to more resolutely put the socialised (or, perhaps more accurately, ensocialled (Higgins, 2017)) body at its centre: that is, the cognitive processes that constitute meaningful human existence are not embodied as a matter of fact or contingency, but as a matter of necessity; crucially, these embodied processes are not ensocialled as a matter of contingency, but as a matter of necessity. The former part of this claim maintains harmony with enactivism but breaks with traditional views that we are (i). cognitive beings who just so happen to be bodied (i.e. the 'orthodox' view that selfhood inheres exclusively in the brain and we could, theoretically, exist as 'brains in vats'), or (ii). cognitive beings who are merely embodied (i.e. the 'modern' view that the body may be causally integral to selfhood, but its role is still one of assistance to all-importance neural faculties). Both of these views privilege the neural system, either relegating the body to a kind of 'shell', or to an extension of the brain. As we will see shortly, the latter part of the claim then diverges from enactivism, as well as breaking with traditional views that we are (i). closed cognitive systems that are merely causally influenced by the 
social world, or (ii). 'openly' cognitive beings who become socialised (whether this be through a constructivist process or some kind of intersubjective constitution). As with consideration of the body, these views are misguided in their consideration of the social world, explicating human sociality as, at best, strongly interconnected with pre-existing agential cognition, or, at worst, as an external framework that merely surrounds agential cognition that is theoretically self-sufficient. Clarifying the non-decouplable nature of 'body' and 'sociality' - and the manner in which this 'body-social' unity constitutes cognition - leads to a more robust conception of selfhood, which, subsequently, leads to empirically supported insights into the mindful maintenance of human wellbeing. ${ }^{3}$

Thus, without abnegating the importance of the neural system, the initial step of the hypothesis presented here is that we are not cognitive beings with bodies, but bodily beings who cognise only in virtue of our bodily nature. The body engenders, pre-figures and regulates any cognitive performance, in ways that frequently evade conscious reflection. A simple phenomenological example of this being made explicit is the surprise that one may feel when executing a sporting action that exceeds one's expectations. Whether knowingly experienced or not, common physiological responses such as blushing, flushing, sweating, trembling, flinching or blanching are all occurrences in which the body constitutively permeates and frames cognition. From a neuroscientific perspective, there is a plethora of findings which support the idea that the body is a constitutive part of cognition, playing a role that frequently precedes or evades reflective awareness. For example, McNeill (1992) has demonstrated that bodily gestures, which accompany almost all speech acts (ibid.), actually anticipate verbal language (ibid., 2000); moreover, when there is conflict between gesture and speech (e.g. someone misspeaks), the gesture retains presentational correctness (ibid., 197). This clearly suggests primacy of the body over explicit thought. Such empirical evidence strengthens Lakoff and Johnson's (1999) seminal work on the body's anchoring and enabling role in human development and use of language. Even pre-linguistically, however, the primacy of the body for cognition cannot be ignored. Damasio (2010), for instance, has described in detail how brainstem structures - notably the nucleus tractus solitarius and parabrachial nucleus - combine with the periaqueductal gray and the superior colliculus brain regions so as to neurally represent any interoceptive changes in the endocrine or autonomic systems (80-86). These internal bodily systems are constitutive of how we subjectively 'feel'; for example, a surge in adrenaline from the endocrine system will make us feel energised, as will the invigoration of an autonomic increase in heart rate or respiration rate. Damasio's (2010) hypothesis is that the aforementioned brainstem structures, which are attuned to endocrinal or autonomic changes, ensure a unity between neural systems and the 'feeling body'. This feeling body is experientially "constant and provide[s] a background to all cognition" (Stapleton,

\footnotetext{
${ }^{3}$ It is important to note that the arguments put forward in Sects. 3 and 4 do not necessarily require acceptance of the picture of selfhood that is being fashioned in this section. That is, the conclusion of the argument can still follow from any non-essentialist view of selfhood, but it most neatly accords with the view of socio-embodied selfhood that is presented.
} 
2013, 8). Supplemental to this view is the grounding of the affective dimension of phenomenology upon robust neurological data.

Collecting such evidence, one is drawn to accede to the view - supported by both phenomenology and enactivism - that the body-as-living-presence is the "center and origin of our being in the world" (Sheets-Johnstone, 2009, 20) and, consequently, cognition can be reconceptualised as an outcome of bodily processes. The sensitive awareness of one's body, which is central to mindful practices (Williams \& Penman, 2011), is thus not only a means of cognising in the form of directed attention to one's own physical presence (e.g. one's breath, one's grounded feet, one's posture, etc.), but also in the form of the very sensorimotor dynamics towards which one's attention is directed.

The pivotal development is to subsequently consider that, phylogenetically and ontogenetically, humans are always embodied beings who exist with others. Humans evolve and develop within a world (an Umwelt) of social tactility, affectivity and collaboration, such that others refine and modulate one's social and embodied cognitive capacities including emotions, attention, and self-consciousness. Yet again, we can see this primacy of human social nature played out phenomenologically and neuroscientifically. From the former perspective, it is notable that several of the bodily responses mentioned earlier - blushing, flushing, flinching, etc. - are typically induced by social circumstances. The primordial role of gesture that was mentioned earlier similarly takes on an indubitable social hue when one considers that gesture is inherently a social act. So, too, does Lakoff and Johnson's (1999) stance on the body's centrality to language, in that they see the true importance of language to be one of providing common cognitive ground amongst human agents. Furthermore, consider that, when alone, one may encounter worldly surroundings as being 'forme', in the sense of affording possibilities for action that are relevant to the kind of biological (or social) self-preservation that was described earlier. Yet, if another is present to the situation, the 'for-me-ness' becomes implicitly modified: in a broad sense, it is no longer an isolated agential act, but one in which the world is encountered as 'for-me-before-another'. In other words, the affordance landscape becomes shot through with the other's potential to also manipulate surroundings (as a cooperator or otherwise), or pass judgement on one's act or presence. Indeed, there is considerable data on neural and bodily responses suggesting that the mere embodied co-presence of another will modify cognitive (Golland et al., 2015) and autonomic behaviour (Qi et al., 2020), which directly ties deeply engrained physiological processes with the social world. In keeping with this, Damasio's (2010) work on the neural underpinnings of the affective body are also directly tied to sociality once one considers that the same brain regions which are attuned to endocrinal and autonomic changes are implicated in social occurrences such as maternal care (Noriuchi et al., 2008), romantic attachment (Bartels and Zeki, 2008) and vocal responsiveness (Jürgens, 1994). Whilst this should not be read as an endorsement of the modular functionality of brain processes, it does, at the very least, meld the pervasive affective 'background to all cognition' with social processes that are highly prevalent in human daily life. Moreover, considering that affect itself is evolutionarily entwined with sociality in a necessary manner, the aforementioned empirical findings give weight to the notion that the human body is only ever 'a body' in the strictly 
physical sense (i.e. Körper) when it is analytically extracted from the collectively mediated social norms that are constitutive of humanity's lifeworld (Ikäheimo, 2009, 36). Lastly, without the body, there is no relational medium in which the generation and modulation of social norms can take place. There is thus ongoing and reciprocal iterative feedback between human embodiment and ensocialment, which are co-constitutive features of socio-embodied existence. If we return to Sheets-Johnstone's claim that the body is centre and origin of human existence, then it is notable that such a notion is permeated by sociality: "movement grounds our practical ways of being in the world and[...] our ways of being with others" (2009, 330, italics added). In other words, the most fundamental manner of being is a social being: a being-bodied-with-others.

Again, it is important to reiterate that this stance is distinct (albeit developed) from both the idea of intersubjective selfhood that is prevalent in phenomenology and the idea of social constructionism that is prevalent in psychology. That is, our social nature is not a supplementary dimension of primordially subjective consciousness, nor is one's psychological make-up derived from others. Instead, the idea of socio-embodiment pivots on the fulcrum of human bodies being agentially predicated on interactions with others and thereby being the incarnation of socionormative identities. Another way of putting this is that there is ongoing regulatory feedback between aggregated individual (inter)actions that give rise to socio-cultural schemata which, simultaneously, canalise individual actions. Each and every human individual thus channels socio-normative processes whilst concurrently modulating these processes through every action. Socio-embodiment of this kind is, therefore, an active process (continuously modulated through engagement with others), rather than solely being a transcendental or underlying feature of being. As such, socioembodiment as presented here can also be distinguished from the socialised bodies of a Bourdiean habitus or Foucauldian discourse (Bourdieu, 1977; Foucault, 1966) in that humans are not passive agents with respect to pre-existing social structures; instead, every human being is an animate node of (continuously created and creating) social meaning. Repeated cycles of feedback between social and individual activity therein mutually shape culture and individual cognition.

For humans, body and sociality thus have a constitutive relationship. Returning to the 'world' that is central to selfhood for both phenomenology and enactivism, this claim amounts to stating that a body-social history of sedimented schemata is brought forth and enacted, in conjunction with one's present circumstances, in any given moment. The human 'body' and human 'sociality' belong to an ontological chiasm: the processes of one belong to, and cannot be separated from, the other without rupturing the very fabric that holds together humanness.

\section{The Socio-embodied Self and Wellness Throughout Life}

Once the non-decouplable nature of 'body' and 'sociality' is properly appreciated, wellbeing, as a property of selfhood, comes to be seen in a new light. Specifically, the maintenance of wellness inheres in the homeostatic maintenance of socio-embodied selfhood (of which there will be more shortly); conversely, many 
impairments of wellness, such as depression, can be explained as disruptions of the socio-embodied self, which has implications for possible therapeutic interventions, such as mindfulness-based practices. It is impairments of wellbeing across different life-stages that will be considered in this section, thereby illuminating the dependence of wellness on the natural fluctuations of socio-embodied selfhood that occur as humans age.

\subsection{Socio-Embodied Wellness During Infancy}

In an appropriately chronological manner, the first insight can be gleaned from neonascence and infancy. It is widely accepted that social tumult at such ages can have grievous repercussions in later life: for instance, neglect of newborns and infants correlates with poor cognitive and linguistic functioning (Spratt et al., 2012), poor social bonding (Sperry \& Widom, 2013), emergence of anxiety (Heimberg, Brozovich and Rapee, 2010) and emergence of schizophrenia (Matheson et al., 2013). Generally, such impairments are accounted for as resulting from psychological damage, but the theoretical underpinnings of such damage are frequently glossed over.

What can be appreciated through the lens of socio-embodied selfhood is that early-life interactions constitute, in part, the bodily schema that is foundational to all cognitive processing. One's bodily schema is a set of pre-reflective sensorimotor abilities for enabling and constraining appropriate bodily movement in response to environmental stimuli (Gallagher, 2005, 24-38). It is generated, at earliest, alongside incipient signs of bodily self-awareness, which occur through activation of vestibular nuclei during weeks six to fourteen of foetal development (ibid.). From birth, one's bodily schema then grows with every action. Even at a neo-nascent stage, a human is already preferentially attuned to maternal presence (Standley \& Madsen, 1990) and one's native language (Moon, Cooper and Fifer, 1993), as well as displaying a wide array of social imitations (Meltzoff \& Moore, 1977; Nagy et al., 2005; Katiz, Meschulach-Sarfarty, Auerbach and Eidelman, 1988). From the first fledgling hours and days of pre-birth existence, then, human neonates appear to be bodily disposed to social presence, further strengthening the non-decouplable nature of socioembodiment (Higgins, 2018).

Moreover, throughout early life, infant-caregiver interactions are polarised such that they are largely exogenous for infants; that is, the scope, rhythm, tone and physical dynamics of interactions are heavily reliant on caregiver behaviour (Krueger, 2013). Resultantly, social adversities are dependent on caregiver activity, not in a mere causal manner, but as constitutive of infant experience: the caregiver assumes an authoritative role of contextual guidance and modulation of the interaction, therein soliciting responses from infants. In this way, there is dynamic 'coupling' between infant and caregiver, with the structure of the infant's experience being regulated by the caregiver's actions (Higgins, 2018; Krueger, 2013). The problem with this in cases such as neglect is that the 'world' that the infant is creating - and which will be enacted in all future activity - is exogenously sculpted by caregiver behaviour. The very foundations of human selfhood are thus dependent on these early-life interactions - inclusive of any neglect, trauma or other adversities - to which one 
is more an 'assistant' than a 'master'. With this premise, it follows that the longer infants are subject to social adversities, the more deeply embedded such dynamical experiences become, in the sense that there is iterative consolidation of the world being brought forth and then enacted repeatedly.

Prompt intervention is thus key to redressing early-life afflictions, so as to disrupt the ongoing generation and consolidation of a harmful phenomenological world. Alongside this, the journey through phenomenology and enactivism to the concept of socio-embodied selfhood (Sect. 2) informs us that the centrality of the body should not be overlooked in therapeutic treatment of early-life social afflictions. That is, from birth, the infantile world is engendered through socio-embodied dynamics that heavily influence one's subsequent development through adolescence and adulthood (Feldman, 2012). To neglect the role of bodily interactive dynamics - the actual behavioural synchrony and affiliative tactility of engagement with others - is to ignore the core of human existence and, therefore, human wellbeing. ${ }^{4}$

\subsection{Teenage Angst}

Whereas the earliest moments of experiential life are exogenously structured, one gradually develops a strong sense of autonomous agency and, by adolescence, most people are beginning to generate at least some beliefs, predilections and behaviours that are independent from one's immediate culture or familial group. It is as this agency comes into its own that many people first experience a kind of existential angst. This is a familiar concept to phenomenologists (see Kierkegaard (1844/1980), Heidegger (1927/1962) and Sartre, 1946/1984)), but it can also be viewed from a common-sense understanding as encapsulating the feelings of concern or distress with regards to one's place and role in life - feelings which frequently lead people to engage with mindfulness. Angst is not something that is medically diagnosed or treated, but it is heavily connected to feelings of anxiety, loneliness, futility and lack of self-worth, all of which should rightfully be thought of as meaningful impairments of wellbeing.

Typically, such angst - provided it does not escalate to adolescent depression or anxiety - is dismissed as simply part and parcel of development: across many cultures, it is simply accepted that there is an 'awkwardness' to being not quite a child or an adult. The well-reported fact that adolescence is a period of notable cognitive, hormonal and emotional change (Blakemore, 2018) further lends itself to the idea that feelings related to angst may just be within the natural course of development. What's more, adolescents are more prone to 'irrational' behaviours, such as taking risks and impulsive decision-making, due to the negative outcome of potential social rejection from peers having greater importance than one's health or possible societal repercussions (ibid.). This goes hand-in-hand with heightened sensitivity towards social interactions (ibid.). When pitted against familial and cultural expectations to

\footnotetext{
4 There are, of course, important ethical considerations when it comes to the role of bodily interactions and tactility in addressing social impairments, but such difficulties in no way downplay the importance of the social body to possible therapeutic interventions.
} 
behave in a communally accepted 'rational' manner, which may require a process of analytical abstraction from one's social milieu, adolescent 'irrationality' leads to a clear existential discordance that could underlie angst.

However, what needs to also be considered in light of socio-embodiment is that physiological changes during adolescence should be incorporated into explanations of social and cognitive behaviours. For instance, dramatic physical change results in heightened awareness of one's body (Meland et al., 2007), which further exacerbates awareness of physical connectivity with others, or lack thereof (Orben et al., 2020). Conversely, social pressures regarding body 'standards' can have profound effects on physiology through health-related behaviours such as dieting (Meland et al., 2007).

From a strictly phenomenological perspective, great physical change naturally aligns with a disruption to one's world. Firstly, if we recall that humans have a bodily schema and an 'affective body' (which are both part of the lived body), then it stands to reason that sudden physical changes are going to modify both one's immediate sensorimotor engagement with the environment and one's relation to the sedimented history of viable action possibilities that one brings forth to any given situation. In other words, due to physical changes, the actions that one's world affords go through a period of tumult during adolescence that is quite unlike anything experienced earlier in life - one that may even eradicate the meaning that one implicitly encounters in the world (see Sect. 4).

Therapeutically, encouraging adolescents to be 'at one' with their bodies, as is the case in mindfulness-based practices (again, see Sect. 4), could be of great value in addressing a wide range of angst-associated afflictions of wellbeing, as could physical connectivity with others (Phelan, 2009).

\subsection{Old Age: Frailty and Loneliness}

Despite the fact that humans are generally living longer, old age is often a marginalised period of existence, both theoretically and in reality. This is strange as there are numerous views of later existence that are, in general, distinguishable from other stages of human life: for example, older persons are often framed as less physically, socially and politically active, despite the fact that many older persons continue to actively contribute to society. To consider such views as philosophically trivial is a serious error.

There are some existing accounts of the relevance of embodied theories to old age (e.g. Katz, 2012; Kontos, 2012) and the negative impact of physical isolation on older persons - with links to conditions such as geriatric depression (Anderson, 2001), anxiety (Beekman et al., n.d), and dementia (Kane \& Cook, 2013). However, the theory of socio-embodied selfhood can add to such discourse by considering the bodily mediation of social processes. For example, whilst there is a well-established connection between the social isolation that is often suffered by elderly persons and a wide range of negative cognitive and physiological occurrences (Arnetz et al., 1983), little theorisation is provided in the reverse direction; that is, the manner in which physical decline can engender social isolation. Consider, for instance, the fact that diminished animacy of older bodies is, simultaneously, a reduction in social 
expressivity, particularly with respect to the linguistic importance of bodies that was touched upon in Sect. 2. Within social interactions, such diminished bodily expressivity will lead to dynamical disturbances, such as a struggle for implicit rhythmic consonance that would typically arise naturally.

Furthermore, recall that interactions during early life - particularly of a dyadic form - can take on a highly polarised character, with caregivers dominating the experiential scope of behaviour (and, therefore, cognition) for infants. The same possibility emerges during interactions involving elderly persons: it is highly likely that reduced bodily expressivity, which may obstruct the kind of rhythmic harmony that comes naturally to many interactions, will limit elderly persons to a 'submissive' role within intersubjective domains.

In spite of evidence extolling the benefits of physical activity in old age, such data tends to focus on the psychological impact of such activity. What is missed is the idea that such activity is a means to prolonging the bodily animacy that mediates existence in an inherently social world, thereby maintaining a positive sense of wellness. Mindfulness is just one such means of extending the kinds of bodily animacy that are essential to social interaction, including attentional mastery (Yuill et al., 2014), physical control (Reed et al., 2020) and social sensitivity (Tiedens \& Leach, 2004).

\section{What makes us well? An Insight from Depression}

In the previous section, numerous afflictions that can occur throughout various stages of life are discussed through the lens of socio-embodied selfhood. Here, depression will very briefly be subject to the same treatment, during which a key insight into the nature of mindfulness - and its bearing on wellbeing - will become apparent.

Typically, depression is treated either as a neurological condition (Singh \& Gotlib, 2014), or in accordance with the biopsychosocial model (Engel, 1977). However, recent research suggests that phenomenology can provide further insights into the condition. For example, Ratcliffe (2018) has suggested that depression is best viewed as an experiential affliction in which the possibilities of one's world become restricted, resulting in "an inability to be with other people in a certain way" (ibid., 123). This is accompanied by disruption of the anticipatory structure of experience, which, in healthy persons, unfolds unproblematically alongside an indeterminate openness to worldly possibilities (ibid.). In depression, Ratcliffe contends that one's world loses its contingency: the open anticipatory structure of experience is closed off; the world is drained of meaning and one feels inescapably estranged from others. ${ }^{5}$ Ratcliffe adds a further phenomenological dimension to this stance with the claim that people with depression often experience profound temporal disturbances

\footnotetext{
5 Similarly, Ratcliffe (2017) describes anxiety as a disruption of affective anticipation: "one anticipates the arrival of something that is dangerous and threatening to oneself" (72) and, what's more, there is a sense of inescapability from this threat.
} 
such that "time has slowed down considerably or even stopped" $(2012,1)$. Both neurological and biopsychosocial explanations (and treatments) of depression tend to be insensitive to such phenomenological insights.

If we remain true to the view of socio-embodied selfhood, then to speak of an absence of "the prospect of self-transformative interpersonal connection" (Ratcliffe, 2018, 134), or disruptions of temporality, is to speak simultaneously of bodily disruptions. Indeed, a loss of social connectivity should more rightly be treated as a loss of bodily mediated social connectivity. Thus, the harmful cycles of cognition that one undergoes with depression, and which entail a disengagement from the social world according to Ratcliffe, are, at the same time, a disengagement from one's body. The loss of contingency to one's world - the indeterminate openness to action possibilities - is a severing of the dynamic interaction between one's bodysocial history of sedimented schemata and one's present circumstances. In this way, depression is an illness of the lived (social-)body: it is an experiential failure to enact one's world as existentially meaningful.

In terms of disrupting such a fundamental existentiale of being human, the structural profundity of depression should never be treated lightly. However, all is not lost. In keeping with one's socio-embodiment, encouraging persons suffering with depression to re-immerse in the sensuous density of the present, thereby simultaneously reconnecting with the social world, will reap benefits. Mindfulness, which has been proven to be as effective as medicine in treating some forms of depression and anxiety (Hoffman, Sawyer, Witt and Oh, 2010), is one therapeutic method that supports this approach. Rather than merely being a process of "paying attention to moment-by-moment events" (Williams, 2008) and thereby halting rumination on negative thoughts, mindfulness is also a means of 're-entering' the lived (social-) body. This inhabiting of one's sensuous bodily presence not only ruptures negative thought cycles, but also returns one to the world's contingent possibilities: the lived (social-)body "is always a source of potential surpassing[...] where novelty, no matter how seemingly trivial, is a perpetual possibility" (Sheets-Johnstone, 2009, 21). The ostensibly simple act of mindful attentiveness, usually directed at some bodily action(s), thus encapsulates a self-transformative process of sensibilisation towards one's bodily potential for social engagement, purpose and meaning. Without this process, there will always linger the potential for one to succumb to negative thought cycles associated with anxiety, stress and sadness. These negative thought cycles are often seen as 'symptoms' of the kinds of impairments to wellbeing that lead many to seek out mindfulness. In accordance with the hypotheses of this paper, such negative thoughts can be appreciated as underpinned by compression of the indeterminate bodily openness to action possibilities that should accompany everyday experience. In other words, one fails to recognise one's body as the perpetual source of experiential transcendence through future-facing, life-affirming actions, which, invariably, are socially permeated.

Interestingly this same approach can provide a theoretical background to other 'alternative' treatments of depression, such as open water swimming, cold water immersion, creative arts, ecotherapy, and general exercise. All such approaches involve an experiential return to the sensuous density of the bodily present and, therefore, a re-inhabitancy of the social world. 


\section{Conclusion}

In its purest form, mindfulness is a practice of meditation wherein one focuses on (a) certain bodily action(s), such as one's breathing, so as to encourage one's attention towards "a sense of absolute stillness" (Williams \& Penman, 2011, 4). This 'encouragement' is a learned back-and-forth process of relaxing to the extent that one's mind may wander and then non-judgementally guiding it back to the chosen focus of one's attention. Through the practice of mindfulness, one "positively affects the brain patterns underlying day-to-day anxiety, stress, depression and irritability so that when they arise, they dissolve away again more easily" (idib., 5). Whilst the practice, purpose and benefits of mindfulness are well understood, it remains undertheorised from the perspective of its phenomenological foundations.

In this paper, this theoretical lacuna has been addressed along three lines of novelty. Firstly, the notion of socio-embodied selfhood has been presented, providing an original explanation of the inseparability of (co-)constituting bodily and social processes so as to deliver an integrated explanation of how we persist as individual animate bodies within societies. Secondly, the frequently ignored connection between the ontogeny of selfhood and one's wellbeing has been brought to light through consideration of three distinct stages of life. Thirdly, the underlying mechanism of mindfulness has been elucidated as a process of inhabiting the sensuous density of one's present physical being and, through this, acquiescing to the world of open social possibilities. In this way, mindfulness achieves a harmonious balance between future-facing social purpose and wellness-inducing awareness of one's body, each of which mutually constrains the other.

From these foundations, it is possible that one can plough terrain for further considerations of wellbeing, particularly with regards to illnesses often considered to be purely neural, such as depression, anxiety and cognitive decline, with the possibility of contributing to the prevention of exclusory diagnoses by focusing on the holistic nature of the self.

Funding Details (In case of Funding) n/a.

\section{Declarations}

Ethical Approval n/a

Informed Consent n/a

Ethical Approval n/a

Open Access This article is licensed under a Creative Commons Attribution 4.0 International License, which permits use, sharing, adaptation, distribution and reproduction in any medium or format, as long as you give appropriate credit to the original author(s) and the source, provide a link to the Creative Commons licence, and indicate if changes were made. The images or other third party material in this article are included in the article's Creative Commons licence, unless indicated otherwise in a credit line to the material. If material is not included in the article's Creative Commons licence and your intended use is not permitted by statutory regulation or exceeds the permitted use, you will need to obtain permission 
directly from the copyright holder. To view a copy of this licence, visit http://creativecommons.org/licen ses/by/4.0/.

\section{References}

Abramova, E., \& Slors, M. (2019). Mechanistic explanation for enactive sociality. Phenomenology and the Cognitive Sciences, 18(1), 1-24.

Arnetz, B., Theorell, T., Levi, L., Kallner, A., \& Eneroth, P. (1983). An experimental study of social isolation of elderly people: Psychoendocrine and metabolic effects. Psychosomatic Medicine, 45(5), 395-406.

Anderson, D. (2001). Treating Depression in Old Age: Reasons to be positive. Age and Ageing, 10, $13-17$.

Bartels, A., \& Zeki, S. (2008). The neural correlates of maternal and romantic love. Neurolmage, 21, $1155-1166$.

Beekman A, Bremmer MA, Deeg D, van Balkom A, Smit J, de Beurs E, van Dyck R, van Tilburg W. Anxiety disorders in later life: a report from the Longitudinal Aging Study Amsterdam. Int J Geriatr Psychiatry.(10):717-26

Blakemore, S.-J. (2018). Inventing Ourselves:The secret life of the teenage brain. Transworld Publishers.

Bourdieu, P., 1977/2016, Outline of a Theory of Practice, trans. R. Nice, Cambridge: Cambridge University Press

Brefczynski-Lewis, J., Lutz, A., Schaefer, H., Levinson, D., \& Davidson, R. (2007). Neural correlates of attentional expertise in long-term meditation practitioners. Proceedings of the National Academy of Sciences, 104(27), 11483-11488.

Capra, F. (1996). The Web of Life: a new synthesis of mind and matter. Anchor.

Casper, M.-O. (2019). Social Enactivism: On Situating High-Level Cognitive States and Processes. De Gruyter.

Damasio, A. (2010). Self Comes to Mind: Constructing the Conscious Brain. Vintage.

De Bruin, L., \& De Haan, S. (2012). Enactivism and Social Cognition: In search for the whole story. Journal of Cognitive Semiotics, 1, 225-250.

Di Paolo, E. (2005). Autopoiesis, adaptivity, teleology, agency. Phenomenology and the Cognitive Sciences, 4, 97-125.

Dreyfus, H., \& Haugeland, J. (1978). Husserl and Heidegger: Philosophy's Last Stand. In M. Murray (Ed.), Heidegger and Modern Philosophy. Yale University Press.

Engel, G. (1977). The need for a new medical model: A challenge for biomedical science. Science, 196, 126-129.

Foucault, M. (1966). The order of things: an archaeology of the human sciences. London: Tavistock.

Gallagher, S. (2005). How the Body Shapes the Mind. Oxford University Press.

Gallagher, S., 2018, 'A well-trodden path: from phenomenology to enactivism', Filosofik Supplement 3

Golland, Y., Arzouan, Y., \& Levitt-Binnun, N. (2015). The Mere Co-Presence: Synchronization of Autonomic Signals and Emotional Responses across Co-Present Individuals Not Engaged in Direct Interaction. PLOS ONE, 10(5), e0125804.

Heidegger, M., 1927/1962, Being and Time, trans. J Macquarrie and E. Robinson, Basil Blackwell

Higgins, J. (2017). Embodied Mind - Ensocialled Body: Revising the body's role for cognitive agency. Phenomenology and Mind, 12, 228-237.

Higgins, J. (2018). The 'We' in 'Me': An account of minimal relational selfhood. Topoi, 39(3), 535-546.

Ikäheimo, H. (2009). A vital human need - recognition as inclusion in personhood. European Journal of Political Theory, 8, 31-45.

Ivanowski, B., \& Malhi, G. (2007). The Psychological and Neurophysiological concomitants of mindfulness forms of meditation. Acta Neuropsychiatrica, 19, 76-91.

Jonas, H. (1966). The Phenomenon of Life: Toward a Philosophical Biology. University of Chicago Press.

Jürgens, U. (1994). The role of the periaqueductal grey in vocal behaviour. Behav Brain Res., 62(2), $107-117$.

Kane, M. and Cook, L., (2013). Dementia 2013: The hidden voice of loneliness. Alzheimer's Society 2013 
Katz, S., (2012) Embodied memory: Ageing, neuroculture, and the genealogy of mind. Occasion: Interdisciplinary Studies in the Humanities, 4

Kierkegaard, S., 1844/1980, The Concept of Anxiety, trans. R Thomte, Princeton University Press

Kontos, P., (2012) Rethinking sociability in long-term care: An embodied dimension of selfhood. Dementia: The International Journal of Social Research and Practice, 11(3):329-346

Krueger, J. (2013). Merleau-Ponty on shared emotions and the joint ownership thesis. Continental Philosophy Review, 46(4), 509-531.

Lakoff, G., \& Johnson, M. (1999). Philosophy in the Flesh. Basic Books.

Lomas, T., Medina, J. C., Ivtzan, I., Rupprecht, S., Hart, R., \& Eiroa-Orosa, F. J. (2017). The impact of mindfulness on wellbeing and performance in the workplace: An inclusive systematic review of the empirical literature. European Journal of Work and Organizational Psychology, 26(4), 492-513.

Marratto, S. (2012). The Intercorporeal Self. SUNY Press.

Matheson, S., Shepherd, A., Pinchbeck, R., Laurens, K., \& Carr, V. (2013). Childhood adversity in schizophrenia: A systematic meta-analysis. Psychological Medicine, 43(2), 225-238.

McNeill, D. (1992). Hand and mind: What gestures reveal about thought. University of Chicago Press.

Meland, E., Haugland, S., \& Breidablik, H. (2007). Body image and perceived health in adolescence. Health Education Research, 3, 342-350.

Meltzoff, A., \& Moore, M. (1977). Imitation of Facial and Manual Gestures by Human Neonates. Science, 198, 75-78.

Nagy, E., Kompagne, H., Orvos, H., Pal, A., Molnar, P., Jansky, I., Loveland, C., \& Bardos, G. (2005). Index finger movement imitation by human neonates: Motivation, learning, and left-hand preference. Pediatric Research, 58(4), 749-753.

Noriuchi, M., Kikuchi, Y., \& Senoo, A. (2008). The functional neuroanatomy of maternal love: Mother's response to infant's attachment behaviors. Biological Psychiatry, 63(4), 415-423.

Orben, A., Tomova, L., \& Blakemore, S.-J. (2020). The effects of social deprivation on adolescent development and mental health. The Lancet, 4(8), 634-640.

Phelan, J. (2009). Exploring the use of touch in the psychotherapeutic setting: A phenomenological review. Psychotherapy (Chic)., 46(1), 97-111.

Ratcliffe, M. (2017). Real hallucinations: Psychiatric illness, intentionality, and the interpersonal world. MIT Press.

Ratcliffe, M. (2018). The interpersonal structure of depression. Psychoanalytic Psychotherapy, 32(2), $122-139$.

Reed, C., Moody, E., Mgrublian, K., Assad, S., Schey, A., \& Macintosh, D. (2020). Body Matters in Emotion: Restricted Body Movement and Posture Affect Expression and Recognition of StatusRelated Emotions. Frontiers in Psychology. https://doi.org/10.3389/fpsyg.2020.01961

Qi, Y., Herrmann, M., Bell, L., Fackler, A, Han, S. Deckert, J. and Grit, H., (2020). The mere physical presence of another person reduces human autonomic responses to aversive sounds, Proc. R. Soc. B. 2872019224

Sartre, J. (1946). Existentialism is a Humanism, trans. A. Cohen-Salal. New Haven: Yale University Press.

Sheets-Johnstone, M., 2009, The Corporeal Turn: An Interdisciplinary Reader, Exeter:Imprint Academic

Singh, M., \& Gotlib, I. (2014). The neuroscience of depression: Implications for assessment and intervention. Behaviour Research \& Therapy, 62, 60-73.

Sperry, D., \& Widom, C. (2013). Child abuse and neglect, social support, and psychopathology in adulthood: A prospective investigation. Child Abuse \& Neglect, 37(6), 415-425.

Spratt, E., Friedenberg, S., Swenson, C., Larosa, A., De Bellis, M., Macias, M., Summer, A., Hulsey, T., Runyan, D., \& Brady, K. (2012). The Effects of Early Neglect on Cognitive, Language, and Behavioral Functioning in Childhood. Psychology (Irvine), 3(2), 175-182.

Standley, J., \& Madsen, C. (1990). Comparison of infant preferences and responses to auditory stimuli: Music, mother, and other female voice. Journal of Music Therapy, 27, 54-97.

Stillwell, P., \& Harman, K. (2021). Phenomenological Research Needs to be Renewed: Time to Integrate Enactivism as a Flexible Resource. International Journal of Qualitative Methods, 20, 1-15. https:// doi.org/10.1177/1609406921995299

Stapleton, M. (2013). Steps to a "Properly Embodied" Cognitive Science. Cognitive Systems Research, $22,1-11$.

Tiedens, L., \& Leach, C. (2004). The social life of emotions (studies in emotion and social interaction). Cambridge University Press. 
Thompson, E. (2007). Mind in Life: Biology, Phenomenology, and the Sciences of Mind. Harvard University Press.

Varela, F., Thompson, E., \& Rosch, E. (1991). The Embodied Mind: Cognitive Science and Human Experience. MIT Press.

Ward, D., Silverman, D. and Villalobos, M., (2017). 'Introduction: The Varieties of Enactivism', Topoi 36(1)

Williams, J. (2008). Mindfulness, depression and modes of mind. Cognitive Therapy and Research, 32(6), 721-733.

Williams, M., \& Penman, D. (2011). Mindfulness: The Eight-Week Meditation Programme for a Frantic World. Piatkus.

Yuill, N., Hinske, S., Williams, S., \& Leith, G. (2014). How getting noticed helps getting on: Successful attention capture doubles children's cooperative play. Frontiers in Psychology. https://doi.org/10. 3389/fpsyg.2014.00418

Publisher's Note Springer Nature remains neutral with regard to jurisdictional claims in published maps and institutional affiliations. 